\title{
Densitometric Evaluation of Different Pulp Capping Materials using the Prodigy DXA System
}

\author{
${ }^{1}$ Riccardo Beltrami, ${ }^{2}$ Luisa Bernardinelli, ${ }^{3}$ Simone Perna, ${ }^{4}$ Mariangela Rondanelli, ${ }^{5}$ Davide Guido, ${ }^{6}$ Claudio Poggio
}

\begin{abstract}
Background: The dependence of dental diagnosis on radiographs makes it important for all materials used in the oral cavity to be radiopaque: they can thus be identified and distinguished from dental structures. The objective of the present study was to compare the radiopacity of different pulp capping materials using an experimental densitometric evaluation (Prodigy DXA system).
\end{abstract}

Materials and methods: Thirty specimens were prepared for each material following manufacturers' instructions. Dentin slices were obtained from freshly extracted premolar teeth. All materials were scanned on a GE healthcare lunar Prodigy and iDXA in routine clinical manner. The assessment of normality was developed by the Shapiro-Wilk test; the Kruskal-Wallis test, and its multiple comparisons, was applied to compare the materials.

Results: Results with $p<0.05$ were considered to be statistically significant. Major differences were registered between the materials and the dentinal tissue.

Conclusion: Materials containing bismuth oxide showed high densitometric values when compared with resin-based materials and with materials containing zirconium oxide and zinc oxide.

Keywords: Densitometric evaluation, DXA, Pulp capping materials, Radiopacity.

How to cite this article: Beltrami R, Bernardinelli L, Perna S, Rondanelli M, Guido D, Poggio C. Densitometric Evaluation of Different Pulp Capping Materials using the Prodigy DXA System. J Contemp Dent 2015;5(3):144-148.

Source of support: Nil

Conflict of interest: None

\section{INTRODUCTION}

The radiopacity of restorative materials is listed as one of the basic requirements for the accurate diagnosis and

\footnotetext{
${ }^{1} \mathrm{PhD}$ Student, ${ }^{2,4}$ Professor, ${ }^{3,5} \mathrm{PhD},{ }^{6}$ Associate Professor

1,2,5Department of Brain and Behavioral Sciences-Section of Dentistry, University of Pavia, Pavia, Italy

${ }^{3,4}$ Department of Public Health, Neuroscience, Experimental and Forensic Medicine-Unit of Human Nutrition, University of Pavia, Pavia, Italy

${ }^{6}$ Department of Clinical-Surgical, Diagnostic and Pediatric Sciences-Section of Dentistry, University of Pavia, Pavia, Italy
}

Corresponding Author: Riccardo Beltrami, PhD Student Department of Brain and Behavioral Sciences-Section of Dentistry University of Pavia, Pavia, Italy, Phone: 390382987941 e-mail: riccardo.beltrami01@universitadipavia.it follow-up in restored teeth. ${ }^{1,2}$ The commonly-used products to seal communications between the exposed pulp and the oral cavity are calcium hydroxide-based materials and mineral trioxide aggregate. ${ }^{3}$ Various methods to rank the radiopacity of restorative materials have been outlined in the literature: McComb and Smith used as a reference the opacity of the metal mold that held their samples while Beyer-Olsen and Ortsavik were the first to introduce, in their radiographs, a reproducible standard for comparison and laid the basis for developing a method that serves as the guideline for radiopacity testing procedures. ${ }^{4-7}$ The inclusion of the image of an aluminum stepwedge, which, with a thickness of $1 \mathrm{~mm}$, is referred to have a radiopacity similar to dentin, made it possible to transform readings of light transmission in the radiograph into an equivalent thickness of aluminum. ${ }^{8-10}$ However, the indicated values refer to a slightly unconventional method of analysis. In the present study, the radiopacity of pulp capping materials was tested with a densitometric technique in order to avoid the use of the aluminum stepwedge and to directly compare the values obtained. The Prodigy dual energy X-ray absorptiometry (DXA) system provides densitometric analyses based on DXA, that is the absorption and interaction between incident photons and the material. Like traditional radiology, the Prodigy DXA system provides bidimensional images of irradiated surfaces overlapping the changes in density inside the material; however, the inclusion of collimation filters, which allow the emission of a single beam through the material, reduces strayradiation and improves the resolution of the measurements which gain high diagnostic sensibility. The Prodigy DXA system is currently used in several applications in body composition analyses and orthopedics because of the information it offers about bone and soft tissues. This information is expressed as bone mineral content (BMC) and bone mineral density (BMD), thus offering a measurement of density of the material irradiated.

The objective of the present study is to compare the radiopacity of different pulp capping materials using an experimental densitometric evaluation. The null hypothesis is that materials tested present similar values of density to that obtained with dentinal tissue. 


\section{MATERIALS AND METHODS}

The materials tested in this study are listed in Table 1. Thirty standardized specimens of each material were prepared in accordance with manufacturers' instructions; in addition, 30 dentin slices $(1 \mathrm{~mm}$ in thickness and $4 \mathrm{~mm}$ in diameter) were obtained from freshly extracted noncarious teeth by using slow-speed diamond disks; these were stored in a $0.1 \%$ thymol solution until used. The teeth were all extracted for periodontal reasons in the Department of Clinical-Surgical, Diagnostic and Pediatric Sciences-Section of Dentistry (University of Pavia). The dentin slices were for the purpose of radiographic comparison with the materials. Dycal Ivory (Dentsply Tulsa Dental, Johnson City, TN, USA), Dycal Dentin (Dentsply Tulsa Dental, Johnson City, TN, USA), MTA Angelus (Angelus, Londrina, PR, Brazil), Biodentine (Septodont, Saint-Maur-des-Fosses, France) and Proroot MTA (Dentsply Tulsa Dental, Johnson City, TN, USA) were mixed and placed into silicon molds measuring $1 \mathrm{~mm}$ in thickness and $4 \mathrm{~mm}$ in internal diameter. The specimens were covered with glass plates on each side to allow for the removal of excessive material. Thirty specimens of Calcimol LC (Voco GmbH, Cuxhaven, Germany) were prepared by condensing the material into silicon molds ( $1 \mathrm{~mm}$ in thickness and $4 \mathrm{~mm}$ in internal diameter). The molds were filled with the light-curing material and a glass slide pressed onto each side to extrude any excess material and to form a flat surface. The distal end of the light guide was placed against the surface of the material and positioned concentrically to the cavity in the mold; the material was then light-cured from the top using the Celalux II (Voco, Cuxhaven, Germany) curing light.
One, standard, light polymerization mode was used for each material: $1000 \mathrm{~mW} / \mathrm{cm}^{2}$ for 40 seconds. The cordless curing unit was maintained at full charge before use and irradiance was monitored periodically by using a radiometer (SDS Kerr, Orange, CA).

The specimens were kept in a chamber at $37^{\circ} \mathrm{C}$ and $95 \%$ relative humidity for 24 hours. Ten arrays were set by collecting three samples for each material in order to scan them with the Prodigy DXA system (GE Healthcare, Madison, WI).

\section{Dual Energy X-ray Absorptiometry Measurements}

All materials were scanned on a GE Healthcare Lunar Prodigy and iDXA in routine clinical manner per manufacturer recommendations. For the Prodigy, Encore software (GE Healthcare, Madison, WI) version 9.2 was used for acquisition and 11.4 for analysis; with iDXA, Encore software version 9.3 was used to acquire scans with version 11.0 used for analyses. The precision assessments were performed in routine clinical manner in accordance with International Society for Clinical Densitometry (ISCD) recommendations.

\section{STATISTICAL ANALYSIS}

Data collected were analyzed with $\mathrm{R}$ software (version 2.15.3, Development Core Team, 2013) and its package pgirmess. ${ }^{11,12}$ The assessment of normality was developed with the Shapiro-Wilk test. The Kruskal-Wallis test, and its multiple comparisons, was applied to compare the materials in order to determine which groups were different (with pairwise comparisons adjusted

Table 1: Characteristics of tested materials

\begin{tabular}{|c|c|c|c|}
\hline Material & Composition & Lot. No. & Manufacturer \\
\hline Dycal Ivory & $\begin{array}{l}\text { Two-paste system made of a base paste (1,3-butylene glycol } \\
\text { disalicylate, zinc oxide, calcium phosphate, calcium tungstate, iron oxide } \\
\text { pigments) and a catalyst paste (calcium hydroxide, N-ethyl-o/p-toluene } \\
\text { sulphonamide, zinc oxide, titanium oxide, zinc stearate) }\end{array}$ & 120717 & $\begin{array}{l}\text { Dentsply Tulsa Dental, } \\
\text { Johnson City, TN, USA }\end{array}$ \\
\hline Dycal Dentin & $\begin{array}{l}\text { Two-paste system made of a base paste (1,3-butylene glycol } \\
\text { disalicylate, zinc oxide, calcium phosphate, calcium tungstate, iron oxide } \\
\text { pigments) and a catalyst paste (calcium hydroxide, } \mathrm{N} \text {-ethyl-o/p-toluene } \\
\text { sulphonamide, zinc oxide, titanium oxide, zinc stearate, iron oxide } \\
\text { pigments) }\end{array}$ & 121003 & $\begin{array}{l}\text { Dentsply Tulsa Dental, } \\
\text { Johnson City, TN, USA }\end{array}$ \\
\hline Calcimol LC & $\begin{array}{l}\text { Light-curing one-component material containing urethanedimethacrylate } \\
\text { resin, calcium dihydroxide, 2-dimethylaminoethyl methacrylate }\end{array}$ & 1244494 & $\begin{array}{l}\text { Voco GmbH, } \\
\text { Cuxhaven, Germany }\end{array}$ \\
\hline MTA-Angelus & $\begin{array}{l}\text { Silicon dioxide, potassium oxide, aluminum oxide, sodium oxide, iron } \\
\text { oxide, sulfur trioxide, calcium oxide, bismuth oxide, magnesium oxide, } \\
\text { insoluble residues of calcium oxide, potassium sulfate and sodium sulfate }\end{array}$ & 24120 & $\begin{array}{l}\text { Angelus, Londrina, PR, } \\
\text { Brazil }\end{array}$ \\
\hline Biodentine & $\begin{array}{l}\text { Powder containing tricalcium silicate, calcium carbonate and zirconium } \\
\text { oxide. } \\
\text { Liquid containing water, calcium chloride (accelerator) and modified } \\
\text { polycarboxylate }\end{array}$ & B06562 & $\begin{array}{l}\text { Septodont, Saint-Maur- } \\
\text { des-Fosses, France }\end{array}$ \\
\hline ProRoot MTA & $\begin{array}{l}\text { Powder: calcium phosphate, calcium oxide, silica, bismuth oxide, Liquid: } \\
\text { distilled water }\end{array}$ & 12001879 & $\begin{array}{l}\text { Dentsply Tulsa Dental, } \\
\text { Johnson City, TN, USA }\end{array}$ \\
\hline
\end{tabular}


appropriately). ${ }^{13}$ Results with $\mathrm{p}<0.05$ were considered statistically significant.

\section{RESULTS}

For dentin, and for each pulp capping material, descriptive statistics of BMD are shown in Table 2 and represented (by boxplots) in Figure 1. The null-hypothesis that the distributions in groups were modeled as a Gaussian random variable was not confirmed by the Shapiro-Wilk test $(\mathrm{p}<0.05)$. The results obtained by the Kruskal-Wallis test, and its multiple comparisons, is reported in Table 3. The Kruskal-Wallis test returned a significant result

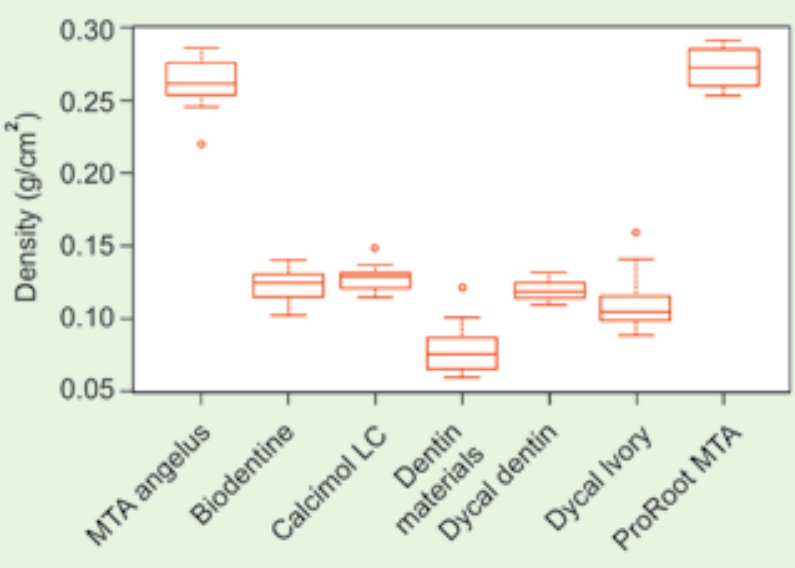

Fig. 1: Box plot of densitometric values for each material tested. The bold horizontal line shows the median value. The top and bottom of the box show the 25th and 75th percentiles, respectively. The vertical dashed lines are called the 'whiskers', they show 1.5 times the interquartile range of the data (i.e. the difference in the third and first quartiles of the observed index). Points more than 1.5 times the interquartile range above the third quartile and points less than 1.5 times the interquartile range are defined as outliers and are plotted individually $(\mathrm{p}<0.001)$; this indicates that at least one of the groups is different from at least one of the others. Concerning multiple comparisons, all the materials, except Dycal Ivory, showed densitometric values significantly higher than dentinal tissue $(\mathrm{p}<0.05)$. ProRoot MTA and MTA Angelus showed the highest values of density when compared with the other materials $(\mathrm{p}<0.05)$. Significant differences were also noted between Calcimol LC and Dycal Ivory $(\mathrm{p}<0.05)$.

\section{DISCUSSION}

The dependence of dental diagnosis on radiographs makes it important for all materials used in the oral cavity to be radiopaque: they can thus be identified and distinguished from dental structures. This property is even more important for pulp capping materials, which are used in contact with pulp tissue. The use of materials less radiopaque than dentin below restorative materials could be radiographically mistaken for decalcified or carious dentin. ${ }^{14}$ Moderately, radiopaque materials are preferable to those with a high degree of radiopacity since the latter may obscure caries-adjacent restorations. ${ }^{15-17}$ It is desirable that restorative materials have radiopacity values similar to that of enamel for better performance. ${ }^{15,18}$ Duarte et al evaluated the radiopacity of Portland cement with different radiopacifying agents; they were added because the original formulation of Portland cement had a low radiopacity, making impossible to distinguish it from bone and dentinal tissues. ${ }^{19,20}$ It was observed that this association is more radiopaque when the following radiopacifying agents were added in decreasing order: bismuth oxide, zirconium oxide, calcium tungstate, barium sulfate and zinc oxide. Therefore, it could be

Table 2: Descriptive statistics for each material tested

\begin{tabular}{lllllll}
\hline Materials & Obs & Mean & Median & Std. Dev. & Min. & Max. \\
\hline Dentin & 30 & 0.0804 & 0.0755 & 0.0183 & 0.0590 & 0.1220 \\
Dycal Ivory & 30 & 0.1132 & 0.1050 & 0.0203 & 0.0890 & 0.1600 \\
Dycal Dentin & 30 & 0.1208 & 0.1190 & 0.0068 & 0.1100 & 0.1320 \\
Calcimol LC & 30 & 0.1293 & 0.1295 & 0.0090 & 0.1150 & 0.1490 \\
MTA Angelus & 30 & 0.2637 & 0.2630 & 0.0180 & 0.2210 & 288 \\
Biodentine & 30 & 0.1248 & 0.1250 & 0.0120 & 0.1020 & 0.1410 \\
ProRoot MTA & 30 & 0.2730 & 0.2740 & 0.0134 & 0.2550 & 0.2930 \\
\hline
\end{tabular}

Table 3: Adjusted p-values and Kruskal-Wallis values (in brackets) obtained for each pairwise comparison between the materials $p<0.05$ corresponded to values of comparison (>47.67) statistically significant

\begin{tabular}{|c|c|c|c|c|c|c|c|}
\hline & Dentin & Dycal Ivory & Dycal dentin & Calcimol LC & MTA-Angelus & Biodentine & ProRoot MTA \\
\hline Dentin & & $>0.05(40.72)$ & $<0.05^{*}(61.90)$ & $<0.05^{*}(89.20)$ & $<0.05^{*}(153.42)$ & $<0.05^{*}(74.02)$ & $<0.05^{*}(162.92)$ \\
\hline Dycal Ivory & & & $>0.05(21.18)$ & $<0.05^{*}(48.48)$ & $<0.05^{*}(112.70)$ & $>0.05(33.30)$ & $<0.05^{\star}(122.20)$ \\
\hline Dycal Dentin & & & & $>0.05(27.3)$ & $<0.05^{*}(91.52)$ & $>0.05(12.12)$ & $<0.05^{*}(101.02)$ \\
\hline Calcimol LC & & & & & $<0.05^{*}(64.22)$ & $>0.05(15.18)$ & $<0.05^{*}(73.72)$ \\
\hline MTA Angelus & & & & & & $<0.05^{\star}(79.40)$ & $>0.05(9.50)$ \\
\hline Biodentine & & & & & & & $<0.05^{*}(88.90)$ \\
\hline
\end{tabular}

* Significant values 
inferred that, depending on the amount and proportion of each radiopacifying agent, more or less radiopaque cement might be obtained. ${ }^{21}$ The comparison derived from the present study highlighted the different influences of the components of each material, largely respecting the information provided in Duarte et al. ${ }^{19}$ Indeed, MTAAngelus and ProRoot MTA showed the highest values in experimental densitometric evaluation, confirming the key role of bismuth oxide-which represents the $20 \%$ of both products. ${ }^{22}$ However, all materials tested showed a significant difference in the densitometric evaluation with BMD against dentin, thus sharing an important property. As reported above, the components which resulted in a higher density to materials when they were scanned with the GE healthcare Lunar Prodigy and iDXA were zinc oxide, contained in Dycal Dentin and Dycal Ivory, and zirconium oxide, contained in Biodentin. Zinc oxide is a well-known radiopacifying agent previously used in restorative and endodontic materials, such as zincoxide-eugenol based cements. ${ }^{23}$ Zirconium oxide, unlike bismuth oxide which has a high intrinsic radiopacity, imparts a lower radiopacity even though it seems to guarantee the clinical requests for this type of dental material. Due to this fact, the high percentage of bismuth oxide contained in MTA-Angelus and ProRoot MTA does not appear to be completely justified; in fact bismuth oxide is not inert but slows the setting time and is a known catalyst for the oxidation of various organic compounds. Moreover, Chan et al have added that a moderate degree of radiopacity is preferable to a high degree. ${ }^{24}$ Very high radiopacity, like that of amalgam, does not provide the best condition for detecting radiolucent areas, such as recurrent caries adjacent to restorations. Calcimol LC is the only resin-based material tested in this study, however it maintains acceptable degrees of radiopacity providing significant differences with dentin tissue.

The main limit of the present study is the low number of dentin samples which do not represent all the individual variations of density and mineral content. The randomized method used when the operator did the extractions should prevent from further limitations and bias.

The strength of the densitometric evaluation provided by the Prodigy DXA System is the ability to minimize measurement errors. Differently from the radiographic evaluation which shows how a material appears in a bidimensional format, BMD values show which is the material density.

\section{CONCLUSION}

The null-hypothesis that all materials present similar values of density to that obtained with dentinal tissue has been rejected because of the significant differences the materials showed when evaluated with the experimental method based on a GE Healthcare Lunar Prodigy and iDXA. Thanks to this method, the values obtained could be directly analyzed without employing the aluminum stepwedge, thus reducing the risk of error. ${ }^{25}$

\section{ACKNOWLEDGMENTS}

We thank the Instituto Santa Margherita (via Emilia 10, 27100 Pavia, Italy) for allowing access to its facilities and machinery useful for the development of the study.

\section{REFERENCES}

1. Grossman LI. Endodontic practice. 7th ed. Philadelphia, PA: Lea and Febiger 1970. p. 85-92.

2. Rasimick BJ, Gu S, Deutsch AS, Musikant BL. Measuring the radiopacity of luting cements, dowels, and core build-up materials with a digital radiography system using a CCD sensor. J Prosthodont 2007 Sep-Oct;16(5):357-364.

3. Dominguez MS, Witherspoon DE, Gutmann JL, Opperman LA. Histological and scanning electron microscopy assessment of various vital pulp-therapy materials. J Endod 2003 May;29(5):324-333.

4. McComb D, Smith DC. Comparison of physical properties of five commonly used root canal sealers. Oral Surg 1967;24: 89-101.

5. Beyer-Olsen EM, Orstavik D. Radiopacity of root canal sealers. Oral Surg Oral Med Oral Pathol 1981;51:320-328.

6. American Dental Association, council on dental materials, instruments and equipment. Specification No 57 for endodontic filling materials. J Am Dent Assoc 1984;108:88.

7. International organization for sandardization. International standard ISO 6876-1986: dental root canal sealing materials.

8. Eliasson ST, Haasken B. Radiopacity of impression materials. Oral Surg Oral Med Oral Pathol 1979 May;47(5):485-491.

9. Goshima T, Goshima Y. The optimum level of radiopacity in posterior composite resins. Dentomaxillofac Radiol 1989 Feb;18(1):19-21.

10. Williams JA, Billington RW. A new technique for measuring the radiopacity of natural tooth substance and restorative materials. J Oral Rehabil 1987 May;14(3):267-269.

11. R Core Team. RA language and environment for statistical computing. R Foundation for Statistical Computing. 2013; Vienna, Austria. ISBN 3-900051-07-0. Available at: http:// www.R-project.org/

12. Giraudoux P. Pgirmess: Data analysis in ecology. R package version 1.5.8. 2013. Available at: http://CRAN. R-project.org $/$ package=pgirmess.

13. Castellan S. Non parametric statistics for the behavioural sciences. 1st ed. New York: McGraw Hill Int 1988. p. 213-214.

14. Prévost AP, Forest D, Tanguay R, DeGrandmont P. Radiopacity of glass ionomer dental materials. Oral Surg Oral Med Oral Pathol 1990 Aug;70(2):231-235.

15. Espelid I, Tveit AB, Ericksson RL, Keck SC, Glasspoole EA. Radiopacity of restorations and detection of secondary caries. Dent Mater 1991 Apr;7(2):114-117.

16. Goshima T, Goshima Y. The optimum level of radiopacity of composite inlay materials and cements. Oral Surg Oral Med Oral Pathol 1989;18:19-21. 
17. Tveit AB, Espelid I. Radiographic diagnosis of caries marginal defects in connection with radiopaque composite fillings. Dent Mater 1986;2:159-162.

18. Sidhu SK, Shah PMM, Chong BS, Pitt Ford TR. Radiopacity of resin-modified glass-ionomer restorative cements. Quintessence Int 1996 Sep;27(9):639-643.

19. Húngaro Duarte MA, de Oliveira El Kadre GD, Vivan RR, Guerreiro Tanomaru JM, Tanomaru Filho M, de Moraes IG. Radiopacity of Portland cement associated with different radiopacifying agents. J Endod 2009 May;35(5): 737-740.

20. Borges AH, Pedro FL, Semanoff-Segundo A, Miranda CE, Pécora JD, Cruz Filho AM. Radiopacity evaluation of Portland and MTA-based cements by digital radiographic system. J Appl Oral Sci 2011 May-Jun;19(3):228-232.
21. Zhang W, Li Z, Peng B. Assessment of a new root canal sealer's apical sealing ability. Oral Surg Oral Med Oral Pathol Oral Radiol Endod 2009 Jun;107(6):79-82.

22. Hashem AA, Hassanien EE. ProRoot MTA, MTA-Angelus and IRM used to repair large furcation perforations: sealability study. J Endod 2008 Jan;34(1):59-61.

23. Tanomaru-Filho M, da Silva GF, Duarte MA, Gonçalves M, Tanomaru JM. Radiopacity evaluation of root-end filling materials by digitization of images, J Appl Oral Sci 2008 NovDec;16(6):376-379.

24. Chan DCN, Titus HW, Chung KH, Dixon H, Wellinghoff ST, Rawls HR. Radiopacity of tantalum oxide nanoparticle filled resins. Dent Mater 1999 May;15(3):219-222.

25. Watts DC, McCabe JF. Aluminium radiopacity standards for dentistry: an international survey. J Dent 1999 Jan;27(1):73-78. 